\title{
Accountability and Reporting for Sustainability and Public Value: Challenges in the Public Sector
}

\author{
Lodovico Gherardi ${ }^{1}$, Anna Maria Linsalata ${ }^{1}\left(\mathbb{D}\right.$, Enrico Deidda Gagliardo $^{2}\left(\mathbb{D}\right.$ and Rebecca Levy Orelli ${ }^{3, *}$ (i) \\ 1 Emilia-Romagna Region, via Aldo Moro 52, 40127 Bologna, Italy; \\ lodovico.gherardi@regione.emilia-romagna.it (L.G.); annamaria.linsalata@regione.emilia-romagna.it (A.M.L.) \\ 2 Department of Economics and Management, University of Ferrara, via Voltapaletto 11, 44121 Ferrara, Italy; \\ enrico.deidda.gagliardo@unife.it \\ 3 Management Department, University of Bologna, via Capo di Lucca 34, 40126 Bologna, Italy \\ * Correspondence: rebecca.orelli@unibo.it
}

check for updates

Citation: Gherardi, L.; Linsalata, A.M.; Gagliardo, E.D.; Orelli, R.L. Accountability and Reporting for Sustainability and Public Value: Challenges in the Public Sector. Sustainability 2021, 13, 1097. https://doi.org/10.3390/su13031097

Academic Editor:

Adriana Tiron-Tudor

Received: 5 January 2021

Accepted: 18 January 2021

Published: 21 January 2021

Publisher's Note: MDPI stays neutral with regard to jurisdictional claims in published maps and institutional affiliations.

Copyright: (c) 2021 by the authors Licensee MDPI, Basel, Switzerland. This article is an open access article distributed under the terms and conditions of the Creative Commons Attribution (CC BY) license (https:/ / creativecommons.org/licenses/by/ $4.0 /$ )

\begin{abstract}
The present study aims at identifying accountability and reporting answers to the public sector challenges surrounding public value and sustainability. To that end, we take into account the Cohesion Policy Programmes, the EU major investment strategy to understand needs and possible answers in terms of accountability and reporting of the public sector. Particularly, we will consider how a specific policy, the cohesion policy, takes place in practice in the Emilia-Romagna Region case, one of the most advanced European regions in terms of capacity in managing funds received by the EU Cohesion Policy. The Emilia-Romagna Region experience shows the extent to which it planned forms of accountability and reporting that hybridize two of the most recent sustainability developments, integrated reporting and sustainable development goals, as a means to deliver sustainability and public value.
\end{abstract}

Keywords: accountability; reporting; public value; sustainable development; integrated reporting; sustainable development goals; Emilia-Romagna Region

\section{Introduction}

The European answer to globalization is represented by the cohesion policy $(\mathrm{CP})$, the most important investment strategy in the EU used to promote and support the 'overall harmonious development' of its Member States and regions [1]. The present research aims to identify accountability and reporting answers to the public sector challenges in terms of public value and sustainability in the $\mathrm{CP}$, considering the Emilia-Romagna Region, one of the most advanced regions in terms of $\mathrm{CP}$ funds management.

Cohesion means providing greater support to the less developed countries, without precluding further steps forward in the economically more advanced ones. To that end, the European Union promotes the growth of all its member states, the free circulation of goods and people and forms of cooperation useful for the dissemination and adaptation of good practices in different contexts. Local and global are considered [2-4] dialogic elements, where local peculiarities are valued at the European and international level, and internal and external relations and relationships are harmonized.

Cohesion is the leading investment policy of the European Union, with resources amounting to 351.8 billion euros (programming period 2014-2020), about one-third of the total EU budget. It has the aim of supporting the creation of jobs, competitiveness between businesses, economic growth, sustainable development, and the improvement of the quality of life of citizens in all regions and cities of the European Union [5]. Cohesion policy has seven-year cycles, and the 2014-2020 period is currently ending. CP aims to reduce the development disparities between the Member States regions and strengthen economic, social and territorial cohesion. In the official documents [6] and website (https: / / ec.europa.eu) of the European Commission, cohesion policy and regional policy are used interchangeably 
to define the EU's main investment policy. In the present programming period, the main purpose concerns recovery from the economic crisis, focusing on creating new skilled jobs and inclusive society, with reference to the Europe 2020 strategy for growth. The society should be smart, for an economy based on knowledge and innovation; sustainable, for a more resource-efficient, greener and more competitive economy; and inclusive, for an economy with a high employment rate, which favors social and territorial cohesion.

The EU does not have a clear and standardized policy in terms of accountability and reporting. Although the objectives of the Cohesion Policy $(\mathrm{CP})$ are economic, social and environmental, there is a lack of a systemic vision for all Member States and Regions of the European Union on how to carry out public value, accountability and reporting to pursue a unified vision on the one hand, but also with a specific focus on the objectives of this policy. Understanding of the public value created by communities and citizens cannot only be generated through reporting on properly spent financial resources. Despite the importance of the $\mathrm{CP}$ and its impact on EU regions, there are no studies focusing on the accountability and reporting strategies of the Regions who use CP funds. Our research would like to fill in that research gap. Through reporting and accountability initiatives, it is undoubtedly given what will be done, what is being done and what has been done with the resources of the cohesion policy, without relying on methodologies and models that can account for the value created in economic-financial, social and environmental terms, demonstrating how institutions have also grown in terms of administrative capacity in this respect.

Territorial cohesion is not all "about the money" [7], as the massive use of cohesion funds has not made the European Union closer to citizens. Euroscepticism grew in many European Union countries, and in the UK Brexit became a reality. Despite being supported by substantial European resources, some British areas, as Cornwall and South Yorkshire, voted for leave [8]. These considerations reinforce the need to identify proper accountability and reporting strategies to disclose sustainability and public value created for citizens using European funds.

To understand accountability and reporting in the $\mathrm{CP}$ of EU regions, we have to turn to practice. To that end, we considered the Emilia-Romagna region experience. In the programming period 2014-2020 of the CP, the Emilia-Romagna Region participated in the programming and managing the programmes of the Investment Objective for growth and employment (mainstreaming) and of the European Territorial Cooperation (ETC) objective. ETC, better known as Interreg, is one of the two goals of cohesion policy and provides a framework for the implementation of joint actions and policy exchanges between national, regional and local actors from the different Member States. The Regional Operational Programmes of the European Regional Development Fund and the European Social Fund (ERDF and ESF ROPs) are directly dedicated to developing the regional territory, and the Interreg ADRION programme is dedicated to the Adriatic, Ionian and Western Balkans area. With resources of about 2.5 billion euros, Emilia-Romagna is one of the European regions that achieves better outputs and results.

To understand how to respond to the challenge of accountability and reporting in the public administration that is capable of representing the different dimensions-economic, social, environmental and governance-of the impacts of the Cohesion Policy, two implementation tools of the Emilia-Romagna Region are analysed: the ERDF Regional Operational Programme (ERDF ROP), which finances interventions on the regional territory, and the Interreg ADRION Programme, which finances transnational projects in the Adriatic, Ionian and Western Balkans. The analysis, in anticipation of the new programming period of the Cohesion Policy 2021-2027, will take into account the needed changes to make the coordination of European Union funds effective with the objectives and targets of sustainability and value creation, and to allow the public administration to show and account for its ability to generate economic, social and environmental impacts.

This paper builds on the literature about accountability and reporting in the public sector aimed at identifying a possible solution for measuring and disclosing, from both an internal and external perspective, the public value of public sector organizations in 
the three dimensions of economic, social and environmental elements and analyses the implications of sustainability on the EU investments in public sector organizations. The research design is based on a change model, namely the context-content-process model of strategic change; it helps to identify the strategic changes in terms of accountability and reporting to foster sustainability and public value, particularly fitting in the case of Emilia-Romagna. The results show that the current demands in terms of accountability and reporting from the EU, Emilia-Romagna Region and territories can be satisfied by using a hybrid model of accountability and reporting that is more able to represent the value creation process and results in public sector organization. Also, results show the necessary changes the Emilia-Romagna Region already embraced to address the desired model of accountability and reporting. These results can be of interest for public sector organization managers at any level and stakeholders and can serve to encourage them to develop valuerelated practices. They can also be useful for policymakers and regulators when evaluating the benefits of EU policies concerning the environmental and social practices in public sector organizations.

The paper is structured as follows. The next section presents a synthesis of previous research on value, accountability as reporting in the public sector, and examines the challenges of public sector organizations and their possible public value developments. Section 3 presents the methodology, research design and context. Section 4 contains the analysis of the results and the discussion. The last section draws some conclusions, highlighting the research contributions, the way forward, and limitations.

\section{Literature Review on Value, Accountability and Reporting in the Public Sector}

Academic studies of public sector accounting have seen enormous developments over the past three decades [9-12]. A specific area of study is public sector accountability and related value, accounting and reporting. Accountability in the public sector is a complex concept with different dimensions [13-15]. The public sector with its multiple stakeholders requires an extensive range of accountability forms toward the value representation, unlike the private sector, and goes beyond the financial dimension, engaging with dimensions such as the political (or democratic), public, managerial, bureaucratic, professional and personal responsibility [15].

Public value theory is now a distinct paradigm from new public management and public governance, and it is considered a new way to conceive the public managers' role [16-18]. Public value discourse has led to the development of different conceptualizations: from public value as a way to contribute to the public sphere [19], to PV as what is added in terms of societal outcomes [20,21], to public value as an actor-focus 'strategic triangle' approach for public managers [22]. However, PV and its theorizing remain ambiguous. In contrast to academia's interest in PV theory, it has been noted that public value management and measurement is a long way from being translated into practice, within and across organizations [20-23]. This may be due to the lack of rigorous empirical research aiming at a deeper understanding of the PV phenomenon, from which new insights and theory-building efforts could be developed [21-24]. In this context, the term PV accounting implies a focus on the definition, justification and measurement of PV generated through the production of public services, from both a theoretical and practical point of view.

Today, the public sector faces global and emerging problems such as climate change, sustainable economic development, modern slavery, tax avoidance, biodiversity and ecological accounts $[12,25,26]$. These issues have been identified as the guiding principles linking concerns for the environment and for the development of humanity [27]. Interdisciplinary accounting scholars should study how public sector accounting and accountability can respond to the challenges posed by the changing and increasing role of the immaterial public dimension [12], for example, using an alternative accountability mechanism such as Integrated reporting [28-30], which aims to disclose the value created over time (short, medium and long term). Integrated reporting provides the accountability processes and 
operational modes through which public interests and public value are decided, planned and represented in the space of common synthesis [31].

Scholars [32] have listed the seven contemporary challenges that public sector organizations face in terms of accountability and reporting. Each challenge embeds specific actions to embrace in terms of public value. The first challenge is represented by the traditional financial reporting [33], which provides a representation of the financial statements. For the public sector, with the advent of the organizational and managerial theories of new public management, a financial reporting model borrowed from the private sector has developed. Several countries have developed their accounting standards that define guidelines for the preparation of public budgets. The focus on just the traditional financial report should be supplemented by standards and reports on social benefits and public value [33] to avoid underrepresentation of the value and contribution of the public sector.

The second challenge is represented by the management accounting that is at the basis of the performance management systems in the public sector, and that can link the budget to various output and result metrics [34]. Some scholars [35], in their examination of the change in the nature of public budgets in recent decades, observed how management accounting has changed from a traditional budget perspective in which the budget role is limited to decide how much to spend on what, to one which involves limiting expenses to available revenues and avoiding high costs. Since the beginning of 2000, the budget started working as a stimulus for the economy and society, a governance and managerial territorial device and the primary accountability tool in the public sector. Another area of challenge is represented by the need to improve the quality of public service delivery [36], particularly after the 2008 financial crisis which required the public sector to contrast expenses and quality of public service delivery [37]. The sheer complexity of, and the oversimplistic approach to, performance management in the public sector makes performance management quite tricky.

The third challenge is the broad area of non-financial information required by the directives of the European Commission. Directive 2014/95 of the European Union regulates the disclosure of certain organizational practices and performances [38,39]. The Directive requires non-financial information to help measure, monitor and manage the performance of businesses and their impact on society [6]. The Non-Financial Reporting Directive requires that public sector organizations disclose in reports such as annual reports, sustainability reports and integrated reports five areas of relevant information related to the environment, social and employee aspects, human rights, anti-corruption and bribery, and diversity on the board of directors. The Directive requires organizations to report on performance and impacts relating to non-financial issues, which is strongly related to different aspects of public sector value [40]. According to the EU Commission, to disclose information, organizations can make use of any reporting model they wish to use, following different national or international guidelines, such as the UN Global Compact, the OECD guidelines or the ISO 2600. At present, the GRI Global Reporting Initiative standards are the most commonly used framework [41]. The guidelines and standards have improved internal public sector processes [42].

The fourth challenge consists of the Integrated Reporting framework and integrated reporting practices. The Integrated Reporting Framework (IRF) integrates financial and sustainability information in one report [43]. The integrated report "improves understanding of the relationships between financial and non-financial factors that determine an organization's performance and how an organization creates sustainable long-term value by disseminating material information about an organization's strategy, governance and performance" [43]. The International Integrated Reporting Council (IIRC) states that more than 1000 companies around the world have prepared an integrated reporting form [30,44]. IIRC and its supporters expect IR to represent the future of corporate reporting and will become the "corporate reporting norm" [43]. The belief that underlies IR is that it is a wide range of factors that determine the value of an organization [45]. Some of these factors are financial and are accounted for in financial statements; others such as intellectual 
capital, risks related to climate change, and energy security are not and must be accounted for otherwise. The action of communicating, in the original text "disclosing", indicates another principle of great importance for the public sector, which means opening up, being transparent and allowing and facilitating dialogue within the organization and between the organization and the external environment. It is clear that the needs and changes that have characterized the public sector for some time converge here and that it is urgent to report and to take responsibility for the planning and implementation of policies [46].

The fifth challenge is the Social and Environmental Accounting, a process of accounting for the social and environmental that affects the actions that organizations perform towards specific groups of stakeholders and society in general [28]. Social and Environmental Accounting emphasizes the concept of corporate responsibility. It is an approach to the reporting of the activity of a company that emphasizes the need to identify socially appropriate behaviours, the determination of the subjects to whom the organization must be accountable for its social performance and the development of appropriate reporting measures and techniques [47].

The sixth challenge proposed by Guthrie and Sardesai [32] is represented by the United Nations Sustainable Development Goals or, in abbreviated form, SDGs, and the various tools used to disseminate the information related to them. In 2015193 countries of the United Nations General Assembly adopted an Agenda for Sustainable Development for People, the Planet and Prosperity called "Transforming our world. The 2030 Agenda for Sustainable Development" consisting of 17 Goals for Sustainable Development Goals (SDGs) in an extensive action program, including a total of 169 'targets' or milestones. The SDGs represent a common language at an international level with which to promote, monitor and report the actions of various governments by deeply connecting the social, economic and environmental aspects with a view to the sustainable development of the territories [48].

The seventh challenge is represented by the public value reporting area. The public value represents the value produced for the community. The value for the public is the result of the evaluation of how the actions of the public sector affect the satisfaction of the basic needs of individuals, groups and society as a whole. It parallels public sector management success with starting and remodelling public sector organizations in ways that increase their value to the public in both the short and long term [22]. Public value echoes and, in a way, sums up some of the previous challenges; the IR in terms of value creation over time and the Agenda 2030 objectives with the objectives of the public sector organizations. Public value is an inter-spatial (that is, it is aimed at different categories of stakeholders in public action) and inter-temporal concept (that is, it focuses on the citizens of today but also looks to those of tomorrow). To improve the external impacts of its action, a Public Administration must also monitor and develop the state of its resources, through administrative improvement projects (internal impacts). The adoption of advanced operating methods that allow for continuous growth in terms of effectiveness and efficiency of the administrative activity depends inextricably on the quantity and quality of available resources. We can therefore deduce that the public sector creates Public Value when it is capable of jointly improving both the wellbeing of users and stakeholders and the health of the body itself, not limited to the episodic generation of utility for today's citizens, but by increasing the ability of the institution to create public value also for the citizens of tomorrow, according to a principle of intergenerational equity [49].

Public sector organizations have the responsibility to pursue the objectives of the 2030 Agenda, due to their responsibility to promote wellbeing and equity, which is an addition to their regulatory power $[25,38,41,50,51]$. In more recent years, the $<$ IRF $>$ is used by numerous public sector organizations, with a clear connection to the SDGs, producing a sort of hybrid disclosure (IR and SDGs-related) that has enriched the value representation potential $[52,53]$ in the public sector. Various authors $[29,54-58]$ examined the practice of the newest and challenging reporting challenges like Sustainability reporting, Integrated reporting and SGDs reports. GRI emerges as a standard in the field of sustainability reporting, and the IR framework is consistently increasing [59]. Also, international organizations that 
deal with accounting $[60,61]$ and consulting bodies $[59,62]$ deepen the effects of reporting models in practice.

\section{Method, Research Design and Context}

The present research is about the forms of accountability that can make the social, environmental and economic impacts of a public administration "accountable" and it is extremely recent. The forms of accountability, as such, are still not very widespread, sometimes adopted on an experimental basis, especially in public administration. In such conditions, in which the outlines of phenomena are recent research, should focus on the in-depth analysis of these phenomena, to allow them to fully appreciate their specificities. Yin [63] indicates that in these contexts, the technique to be adopted is the qualitative one, which allows one phenomenon to be studied in depth in its specificities.

For the purpose of the study, the use of a case study is particularly fitting. The case study can be defined as a research methodology that focuses on understanding the dynamics in a management situation [64]. It is an empirical methodology 'that investigates a contemporary phenomenon within its real-life context when the boundaries between phenomena are not clearly evident and in which multiple sources of evidence are used' [63] (p. 23). The case study allows the researchers to develop an in-depth understanding of complex phenomena and causation in practice [63,65]. As Lincoln and Guba [66] and Guba and Lincoln [67] suggest, a case study offers working hypotheses whereby the appropriateness for understanding other cases can only be assessed by comparing the similarities between the source case (the studied organization) and target cases (other organizations). The same authors highlight the limits in drawing inferences about the generality of findings from a case study. The case study selection is based on the following elements: the presence of long and consolidated experiences in reporting (both financial and non-financial reporting), an organization in the public domain and the availability of the organization to disclose further information if needed. Therefore, the Emilia-Romagna Region was selected for the analysis, satisfying the abovementioned requirements.

As for the primary sources used in the case analysis, the documents collected fall into the following categories: financial statements, documents published on many websites, programmes, regulations and laws, administrative reports, code of ethics, public accessible data and dashboards and sustainability reporting. For the development of the case, the first step was represented by the construction of an event history database [68], built up by ordering the main actions and facts relevant to the introduction of sustainability and public value chronologically, and triangulating different sources to ensure convergence of data. This has allowed the reconstruction of 'who did what and when' and it is the basis of the chronology of events presented. In reconstructing the timeline, we have tried to understand what events led to the decision to introduce and progress sustainability in the organization. It also helped to clarify by whom they had been taken forward, because of different actions, and how. As argued by Brown and Jones [69] the chronology of events is also fact-based, at least in part, as it is based on an ex post-reconstruction and the partial accounts contained in the documents. The analysis was then developed by comparing the various sources of narratives and assessing accuracy and internal consistency [70].

Our research design is guided by Pettigrew and Whipp's [71] strategic change contextcontent-process model. The "context" dimension refers to the "why" of change, and it can be internal and external. The context is external when it considers the supranational or national regulation and the economic, political and social context; the context is internal when it takes into account the ongoing strategy, the structure, the culture, the management or political process of the organization which help to shape the process through which ideas for change arise. The "content" refers to the "what" of change, the area or areas of transformation and the targets and assumptions of change. Finally, the "process" is related to the "how" of change, namely, actions, reactions and interactions of interested parties in negotiating the proposals of change, the models of change, the implementation approach and the patterns through time. The rationale for employing this model as a 
data-collection framework is that sustainability implementation requires change at both strategic and operational levels [72]. The model is widely used to analyse public sector change programmes [73-76]. The model's basis is the contention that these three dimensions are interrelated and any study in the public sector organizations must consider all three dimensions.

The research context, as already introduced, is the Emilia-Romagna Region, in Italy. With almost 4.5 million inhabitants, Emilia-Romagna is located in central-northern Italy, in the heart of the most industrialized area of the country with serious environmental issues. It, therefore, boasts a geographical position of connection between the north and south of Italy and between the Mediterranean and Northern Europe. A region is called to action by the EU following identified steps: there is a chain of institutional steps that starts from the principles of the EU common strategic framework, passes through the negotiations that begin with the Commission's position paper on the situation of individual states. The negotiation ends with the approval of the Partnership Agreement, prepared in collaboration with central and local institutions and economic and social partners, which defines spending strategies, methods and priorities. Following this path, the Commission proceeds with the approval process of the individual national and regional operational programs. Within this logic, four European macro-regional strategies have been defined, which have become the basis for defining the 2014-2020 and 2021-2027 programming.

In the programming period 2014-2020, the Emilia-Romagna Region acts as the Managing Authority of the ERDF Regional Operational Programme and of the Interreg ADRION Transnational Programme. During the period 2014-2020, both programmes, being the main tools for implementing the Cohesion Policy, are called upon to contribute directly to the development of territories and to the cohesion of the European Union, increasingly focused on sustainable development. Also, the mainstream (ERDF ROP) operates at the national and regional level and directly addresses local development issues. Interreg, in its various forms - cross-border, transnational and interregional, faces problems that transcend national borders. The two types of programmes are therefore closely related in their mission of creating public value, and it is in the dynamism between local and global that the knowledge and innovative drive are generated which are the added value for the realization of sustainable development of the territories.

The ERDF ROP is one of the mainstream programmes managed directly by the regional administration. It is part of a multilevel governance context that starts from the common strategic framework, where the main programming lines are defined at the European level, passes through the definition of a partnership agreement between the Member State and the European Commission, in which the investment lines to be applied at the national level, and arrives at the drafting of the regional operational programme which identifies specific actions to be developed in the local area. With reference to the ERDF ROP, the programming cycle was analysed, from the definition of the objectives to the methodologies and practices of monitoring, evaluation, reporting and communication, and involvement of stakeholders. The Interreg ADRION, within the same strategic framework of ERDF ROP, is part of the cooperation programmes that aim to solve problems that transcend the national dimension and to overcome the constraints and obstacles due to borders and which they require common solutions, to be developed jointly between partners from different nations, at a supranational level. Interreg-in territories with similar problems, but often disconnected from each other-finances system actions, networks, agreements, master plans, to trigger synergies and find feasible solutions at the local level, through other community instruments, including those of the mainstream programmes.

The selection of the ERDF ROP and Interreg ADRION programmes of the EmiliaRomagna Region is based on the presence of a long and consolidated experience in reporting or monitoring the progress and implementation of the intervention in different areas, financial and non-financial (i.e., physical and procedural), within a Regional public organization, which feels the need to organize and make available the results of its policies as a contribution to the creation of value and to have them fully recognized by 
the reference communities. ERDF ROP and Interreg ADRION refer to the same Cohesion Policy, to the same financial instrument and to the same institution acting as managing authority. For ERDF ROP and Interreg ADRION, there are different forms of reporting, mostly aimed at verifying the correctness of the spending process, rather than the real impact on the territory, already required by the EU. On the other side, EU and the States are more involved in the general rules and frameworks, and less on the territorial and local stakeholder involvement. Given this approach, multiple reporting experiences have also been carried out with regard to segmented stakeholders, up to the general public and citizens, but a systematic view is lacking.

\section{Results and Discussion}

\subsection{The Context of Accountability and Reporting for Sustainability and Public Value}

The context of change can be external or internal. The international (EU) and national (Italian) external economic, political and social contexts are key elements to understand the forms of accountability of the Emilia-Romagna Region to answer to the socio-economic and territorial scenario.

The Cohesion Policy (CP) operates on two levels, European and national, giving life to a multidimensional system based on vertical and horizontal subsidiarity, as the way to attribute of concurrent competences which, together with the principles of decentralization and autonomy, finds flexible application through integrated strategies at multiple levels of government [77].

The $\mathrm{CP}$ works at central and local levels to different extents. The concept of cohesion initially included the economic and social dimension, and then, with the Lisbon Treaty, the territorial dimension was added in 2000. Starting from the principle of subsidiarity, it was established that policies must respond to the real and concrete needs of the territories [78], through a process of consultation and participation of territorial stakeholders to create economic, social and territorial value in EU regions. To that end, in the $\mathrm{CP}$ governance is a key element. Institutional relations envisage vertical multilevel governance, ranging from the EU, the State and the Regions, and horizontal, involving different actors from the same territory. On the vertical side, the Parliament and the European Council approve the multi-annual budget of the European Union, which allocates the resources for the $\mathrm{CP}$. At the same time, a process of analysis and discussion on the results of the previous programming starts in the Member States, in order to outline the objectives and guiding actions for the following period. Once the budget has defined and distributed among the Member States, it starts a phase of national and regional actions. The approval of the individual programming documents is a responsibility of the European Commission, after a process of negotiations with States and Regions. Horizontal governance, at the level of the individual territories involved, is essential to ensure correspondence between what is planned and what local communities and territories need because cohesion policy is place-based.

The internal context involves the ongoing strategy, the structure, the culture, the management and the political process which help shape the process through which ideas for change arise. Within the multilevel governance system, there is an ongoing strategy of the institutional, economic and social partnership. It plays a fundamental role, and implies close cooperation between the Commission, the Member States, the social partners and the bodies that represent civil society at the national, regional and local level. During the planning phase, the dialogue between the European Union, States and the Regions, and at the territorial level, the involvement of stakeholders is quite consolidated, with interesting and advanced evidence in various contexts. The stakeholder consultation and engagement is required in the programme approval procedures according to the Common Provision Regulation (Regulation (EU) No. 1303/2013) and to the European Code of Conduct on Partnership in the framework of the European Structural and Investment Funds (Commission Delegated Regulation (EU) No. 240/2014). The partnership constitutes a clear added value in contributing to the effective implementation of the European Structural and 
Investments (ESI) Funds, involving it throughout the programming cycle-preparation, implementation, monitoring and evaluation-with a focus on the selection of partners, who must be representative of the interested parties and therefore of the stakeholders. The principle of inclusion focuses attention to the involvement of the most vulnerable and marginalized communities, at the highest risk of discrimination or social exclusion. The partnership strategy requires a permanent involvement of the local, territorial actors through agreements in the construction of territorial development paths [79]. The national level is divided into two further levels, regional and local, to manage the partnership strategy. Within this distinction, the Italian Regions play a fundamental role in the management of the political process of development of their territories, being called upon to directly manage shares of the structural funds through regional operational programmes. The ERDF ROP is one of the mainstream programmes managed directly by the regional public authority which identifies specific processes to be developed at the local level.

In the Emilia-Romagna Region, for both the programmes, ERDF ROP and Interreg ADRION, a common regulation (Common Provision Regulation CPR) is envisaged. It defines precise and punctual evaluation criteria, financial and output indicators and specific rules that regulate their peculiarities. Both financial and output assessment plans are mandatory for both programmes. These assessments are carried out through indicators established at the European level (with few adjustments on local peculiarities), chosen from sets common to all priorities. Therefore, the direct and short-term results are measured, in a way not always appropriate to the specific intervention line, and the medium-long term impacts are not taken into consideration. The Emilia-Romagna Region, within the framework of the unitary programming, expressed by the Regional Strategic Document, has established the unitary Regional Evaluation Plan, in which the system of overall evaluations and specific evaluations is foreseen. Regional assessments, still in progress, also highlight the limits mentioned above.

The last element of context that has a strong connection with sustainability and public value is represented by recent actions undertaken to contrast climate change and environmental degradation, which are considered the main problems of the current period of human history, and whose consequences will force to adapt/modify the way of living and working. To that end, the Green Deal launched in December 2019 by the new President of the European Commission, Ursula von der Leyen, provides for a multisectoral commitment to become, by 2050, the first continent with zero impact on the climate [80]. "The European Green Deal is the European Union's response to the climate and environmental-related challenges that are this generation's defining task. It is a new growth strategy that aims to transform the EU into a fair and prosperous society, with a modern, resource-efficient and competitive economy where there are no net emissions of greenhouse gases in 2050, where the environment and health of citizens are protected, and where economic growth is decoupled from resource use" [81]. Through research and innovation, the European Union intends to become a world player in the circular economy and clean technologies. To that end, it would drive a just and socially fair transition to the low carbon economy, applied above all in industrial sectors with high energy intensity, defining clear priority of intervention for Regions. In this respect the Emilia-Romagna Region would be enormously affected by the new scenario, given the production intensity of the Region.

\subsection{The Content of Accountability and Reporting for Sustainability and Public Value}

The content of accountability and reporting for sustainability and public value is linked with the main areas of transformation of the $\mathrm{CP}$, and with the targets and assumptions about that change.

The traditional accountability and reporting rules are embedded within the Regulation (EU) no. 1303/2013. It contains the standard provisions to all financial instruments relating to the $\mathrm{CP}$ for the period 2014-2020. It identifies 11 common thematic objectives that must be translated into specific priorities in each operational program. Within each operational programme, financial and output indicators must then be identified, the level 
of achievement of which defines the performance of the programme, and are reported to the Commission through annual reports. In terms of financial accounting challenges, the Emilia-Romagna Region has clear rules to follow.

It is in the reporting function that margins for improvement and practices have been identified [82], to be defined to ensure the sharing of the results achieved and to be achieved, compared not only with the European context but also with the global and international one. In reporting, the most currently represented dimension is the financial one, above all to avoid, on the part of those who manage the individual programs (States and Regions) having resources reduced, as they are not spent on a schedule. For both ERDF ROP and Interreg ADRION financial and impact assessment are mandatory in the 2014-2020 programming period. These assessments are carried out through indicators established at European level (with few adjustments on local peculiarities), chosen from sets common to all priorities. Therefore, the direct and short-term results are measured, in a way not always appropriate to the specific intervention, and the medium-long term impacts are not taken into consideration, not allowing an integrated view of the effect of action realized on the social, environmental and governance levels.

In the period 2014-2020 of the CP we can sum up that in the Emilia-Romagna Region there was a need for knowledge in terms of financial accounting based on cash inflows and outflows, but no needs in terms of management accounting. Also, there was no need to follow the EU directive's requirement on non-financial information and diversity, even if there is a need of pre-defined indicators linked with non-financial information, mainly social and environmental impacts of the actions achieved. Under this perspective, the EU directive on non-financial information does not challenge the Emila-Romagna Region.

The first tension to change in the content of accounting and reporting started with the SDGs. The European action in favour of sustainability has begun a phase in which the 2030 Agenda is part of European policies and is part of the ongoing debate for the definition of the 2021-2027 programming period. In 2015, when 193 UN countries adopted the 17 Sustainable Development Goals (SDGs), the SDGs have started to influence EU policies and the Cohesion Policy. The European Union attention to the SDGs is testified by the numerous initiatives, acts and documents approved from 2016 onwards. In 2016, with the Communication COM (2016) 739 final of the European Commission "The sustainable future of Europe: next steps". The development goals for Europe present a multidimensional perspective, which combines and integrates the economic dimension with the social, environmental and institutional one. After having joined the 2030 Agenda, the European Commission released in 2016 its first reflections in the document "Towards a sustainable Europe by 2030". Following the EU path, the Emilia-Romagna Region started its thinking on sustainability from the SDGs challenge.

Due to the SDGs' influence, the new regulatory framework 2021-2027 for the CP shows some distinctive elements in comparison to the past situation [83]. During the 2014-2020 period, the focus of the CP was on overcoming the 2008 economic crisis with an emphasis on work and employment, while for the period 2021-2027, it identifies three priority macro-areas: sustainability, research and innovation, and the digital. The 11 thematic objectives of the 2014-2020 programming have been consolidated into five objectives thanks to a process of simplification and concentration, they are a smarter Europe, through the promotion of an innovative economic transformation and intelligent; a greener, low-carbon Europe, through the promotion of a transition to a clean and fair energy, green and blue investments, the circular economy, adaptation to climate change and risk management and prevention; a more connected Europe-a more connected Europe, through the strengthening of mobility and regional connectivity to information and communication technologies; a more social Europe-a more social Europe, through the implementation of the European pillar of social rights; a Europe closer to citizens-a Europe closer to citizens, through the promotion of sustainable and integrated development of urban, rural and coastal areas and local initiatives. 
After the European elections in 2019, the President of the European Commission has repeatedly reiterated the need to put people at the centre of politics. The European Green Deal aims to improve people's wellbeing, to make Europe climate neutral by 2050, to protect natural heritage, with benefits for people, the planet and the economy. The European Green Deal is a paradigm shift concerning the way of living, consuming and producing in EU countries, a great challenge and opportunity. The messages of the President of the European Commission are very clear in this regard: "The European Green Deal is our new growth strategy. It will help us cut emissions while creating jobs" [84]; and First Vice President Frans Timmermans: "We propose a green and inclusive transition to help improve people's wellbeing and secure a healthy planet for generations to come" [84]. With the Green Deal, the Commission then provided for the adhesion to Agenda 2030, and the integration of the SDGs which should be at the centre of the process of elaboration and implementation of EU policies. It does not surprise that the opening paragraph of the Commission Communication of 14 January 2020 "A strong social Europe for transitions", makes a direct reference to the SDGs: " ... Social justice is the foundation of the European social market economy and is at the heart of our Union. It underpins the idea that social fairness and prosperity are the cornerstones for building a resilient society with the highest standards of wellbeing in the world, as also reflected in Europe's ambition to progress towards fully meeting the United Nations' Sustainable Development Goals" [85] (p. 1).

At the level of the Emilia-Romagna Region, ERDF ROP and Interreg ADRION, even if to different extent and focus, must act to ensure widespread wellbeing and fairness in its interventions. It is essential to link interventions with a composite and varied audience of stakeholders, to deliver effective solutions in the various territorial areas. In turn, it can be easily understood that the accountability of the public administration managing those programmes cannot focus only on the financial dimension: it must include the transformations that can be supported by its action at the economic, social, environmental and governance levels and SDGs. The impact indicators for the evaluation of the interventions proposed in the 2014-2020 programming period are however still linked to the direct impact of the intervention on the recipients (immediate or short-term effects) and not always appropriate to the topic for which they are used as they are chosen between sets of indicators common to all priorities.

Another element of transformation in the content of accounting and reporting is envisaged in the need to show how links are created between institutions and stakeholders from different countries, how methodologies of action and planning models are shared, and how operational proposals and guidelines are drawn up, which sometimes lead to the signing of agreements and which can represent the basis for new models and new practices to be implemented locally. Likewise, the experiences and good practices developed by regional programmes can be compared on a global level and become an element of dissemination, adaptation and development of the CP. The stakeholder participation is certainly one of the most relevant aspects in the intertwining and dynamics of ERDF ROP and Interreg ADRION. The programmes may face territories with similar problems, but often disconnected from each other, from which it descends the need of finances system actions, networks, agreements and master plans, in order to trigger synergies and find feasible solutions at the local level, through other community instruments.

The accountability and reporting challenges for sustainability and public value involved in the ERDF ROP and Interreg ADRION programmes requires impact measures, stakeholder activities and the sustainability priorities of the EU, and offers a direct link with SEA, sustainability reporting, integrated reporting and public value. Some accountability and reporting tools are already in use by the Emilia-Romagna Region. Still, they are mainly limited to financial reporting and management accounting, as they are required by the specific regulations of the $\mathrm{CP}$. As for the assessment of the impacts of the funded interventions, it is becoming increasingly important, and it is crucial to strengthen and better structure the relationship and the constant and functional involvement with stakeholders, with whom to discuss, monitor and evaluate the activities carried out, as well as the new development 
dynamics. For the Emilia-Romagna Region, a model of this type has already been implemented, first with the Pact for Employment [86] and now with the Pact for Employment and Climate [87], both co-created and signed by relevant stakeholders, with the objective of monitoring, evaluating and promoting together results and impacts achieved. To that end, the Pact for Employment and Climate includes three actions: monitor the progress of the actions taken and assess their impact, starting from a common and uniform database for the whole territory, fundamental in the environmental field; evaluate any additions or changes, starting from new scenarios, new criticalities end opportunities; promote the implementation of the strategies on territories.

Simultaneously, the Pact for Employment and Climate requires the definition of indicators of economic, social and environmental impacts. With them, it will be possible to measure (ex-ante, ongoing and ex-post) results achieved in the strategic areas identified by the Pact. These indicators will be consistent with those that will measure the 2030 Agenda Regional Strategy [87] (p. 35).

\subsection{The Process of Accountability and Reporting for Sustainability and Public Value}

The process of accountability and reporting for sustainability and public value is represented by, namely, actions, reactions and interactions of interested parties in negotiating the proposals of change, the models of change, the implementation approach and the patterns of change through time [88]. The process involves the three main areas of the content of change, already identified, namely the sustainability (and SDGs) turn of the EU and its priorities in the 2020-2027 programmes, the integration of non-financial measures with the financial-ones to measure and communicate the sustainability path and achievements, and the role and effects of stakeholder and participation in the programmes to increase public value.

The SDGs represent a form of accountability able to show the creation of public value of the Cohesion Policy at the local level as they represent a common language to promote, monitor and report the actions of governments by deeply connecting the social, economic and environmental aspects with a view of territory development [48]. It is worth noting that the monitoring of the SDG achievement can be carried out annually worldwide. International organizations such as the World Bank and national and regional statistical institutes are involved in this assessment.

Since there is no direct relationship between the political objectives of European Cohesion and the SDGs, a great deal of work will have to be done to find the cause-andeffect relationships between what is funded and achieved by the POR FESR and Interreg ADRION programs and the progress of the SDGs. This element represents probably the key challenge for the Emilia-Romagna Region in terms of accounting and reporting. It is clearly linked with the Social and Environmental Accounting challenge. Nonetheless, social and environmental tensions are expressed in SDG terms.

The Emilia-Romagna Region, within the framework of the unitary programming, expressed by the Regional Strategic Document, has established the unitary Regional Evaluation Plan, in which the system of overall evaluations and specific evaluations is foreseen. The analysis of the trend in the long term (last ten years) and in the medium term (last five years) of the impacts obtained by the Cohesion Policy instruments on the reference territories, read in the framework of the SDGs indicators, will be able to account for how much these instruments have contributed to the improvement with respect to the SDGs.

The process of accountability and public value in the Emilia Romagna Regions also considers with interest the Integrated Reporting Framework (IRF), in which financial and sustainability information is integrated into a single report [43]. The action of disclosing stated within the IRF indicates a principle of great importance for the Region: opening up, being transparent and allowing and facilitating dialogue within the organization and between the organization and the external environment. In recent years, the IR connection with the SDGs empowered accountability and reporting towards sustainability and public value in public sector organizations $[89,90]$. In the $\mathrm{CP}$, including sustainability 
with a widespread approach worldwide can bring significant benefits to policies and the relationship with the stakeholders.

There are many benefits of combining SDGs and IR [51] to foster sustainability and public value in the Emilia-Romagna Region. To push forward the process, the Region settled down clear strategies of action. The mandate program of the Regional Council, XI legislature, among the actions of the Vice-President Elly Sclein states the need of coordination of the European Union funds and the promotion of European cooperation, with the aim of promoting more effective forms of accountability. To that aim, the actions implemented by $\mathrm{CP}$ have to be linked with the objectives and targets of sustainable development of the 2030 Agenda [91].

The Emilia-Romagna Region is strategizing such initiative in political terms in the Document of Regional Economy and Finance (DEFR), approved by the Legislative Assembly in October 2020 within the strategic objective of Vice-President Schlein "Coordination of European Union Funds and promotion of European territorial cooperation". It states that "The regional development strategies in the context of the Pact for Employment and Climate must be supported by an integrated accountability that highlights the contribution of the European Funds to the achievement of sustainable development objectives and targets of the sustainable development, as well as the ability of the [regional] system to generate economic, social and environmental impacts" [92] (p. 143). Among the expected results for 2021, there is the "Preparation and test of an IRF (Integrated Reporting Framework) to develop the accountability of the contribution of the European funds of the $\mathrm{CP}$ and the Development and Cohesion Fund to the achievement of the regional targets connected to the goals of 2030 Agenda (SDGs)" [92] (p. 145).

The next steps in the accountability and reporting for sustainability and public value in the Emilia-Romagna Region for the next 2021-2027 CP, particularly ERDF ROP and Interreg ADRION, would be the following. In the phase of defining the new programming cycle, the SDGs relevant to the topics dealt with by the ERDF ROP and Interreg ADRION should be identified. The various stakeholders to be involved must be identified and listed in order of relevance. The analysis already started at the regional level with the document "Unified regional strategic guidelines", that can be used for the drafting of the regional operational programs, and territorial cooperation, identifies the territorial needs for future interventions.

Then, it is essential to identify which targets to operate on, among the SDGs identified in the previous phase, and which actions of the ERDF ROP and Interreg ADRION programmes affect the selected SDGs targets, allowing the organization to create public value. Subsequently, within the ERDF ROP and Interreg ADRION, the connections with the identified targets should be highlighted and a specific reflection should verify how the actions and implementation methods provided for can affect the targets in the short, medium and long term. It would be possible to turn the defined accountability and reporting strategy into practice, through the development of integrated thinking that connects operational strategies of the programs with the performances and the effects on SDGs.

To that end, it will be necessary to integrate the mainstream programmes at a regional level with the Interreg programmes in which the mainstream area falls. The integration at the level of the programmes must consequently be connected to the specific development objectives of the Region (mainly the Pact for Employment and Climate). For the constant involvement of stakeholders, a web platform designed for an ongoing dialogue would be crucial. The various levels of Regional governance must also be adequately informed and trained for action according to integrated thinking and the SDGs. In the end, finally, it would be possible to prepare the integrated reporting declined through the SDGs and disseminated on an annual basis and accompanied by specific comparison interventions at international, European and national levels.

The Emilia-Romagna Region will benefit from adopting accountability and reporting tools linked with sustainability and public value. The long and medium-term impacts of the Cohesion Policy on territories, placed in the framework of the SDGs and IR indicators, 
effectively contribute to creating value and citizens' perception of the effects of such policies. The resulting form of accountability, which hybridizes SDGs and IR, allows a holistic and global vision of the regional interventions and shows its ability to generate economic, social and environmental values in the Region. Through a new relationship with society, the hybrid model can also provide a cultural and managerial change of the Region.

\section{Conclusions}

The path towards sustainability and the assumption of responsibility towards current and future generations has become the central political theme of the EU, which launched the European Green Deal. The assumption of the objectives defined by the 2030 Agenda and the related targets in the accountability of the Cohesion Policy therefore becomes necessary to connect territorial development to the issue of sustainability. In the current international context, which requires addressing global and emerging problems with adequate solutions in different territorial areas, the accountability of the public administration must be focused not only on the financial dimension. Still, it must include the representation of the impact that its actions produce on the social, economic, environmental and governance context.

Within that context, the study aimed at identifying accountability and reporting answers to the public sector challenges in terms of public value and sustainability taking into account the cohesion policy, in the case of the Emilia Romagna region, one of the most important European regions in terms of funds received by the EU Cohesion Policy. The Emilia Romagna region experience shows the extent to which it turned to plan forms of accountability and reporting that hybridize two of the most recent sustainability developments, integrated reporting and sustainable development goals, as a mean to deliver sustainability and public value.

From the discussion of the Emilia Romagna experience, it emerged that the integrated vision of SDGs is one of the most relevant aspects in the dynamics of ERDF ROP and Interreg ADRION. However, the integrated approach requires further developments concerning accountability. It is necessary to relate to the public organization, which can plan and manage the interventions and the external environment, where the planned interventions are highlighted. It becomes essential to strengthen and better structure the relationship and constant and functional involvement with stakeholders, discuss, monitor and evaluate the activities carried out, and the new development dynamics and provide clear indications on value creation.

The Emilia-Romagna Region is moving towards a hybrid form of accountability and reporting to show economic, social and environmental impacts. This accountability includes three different founding elements, namely the creation of public value in the short, medium and long term through an integrated reporting of financial and non-financial information; the integration of the actions carried out with the sustainable development objectives and targets (SDGs); the involvement of stakeholders, in particular with stakeholder participation and public engagement processes. The phases with which to implement the model to the case studies analysed can be summarised as follows: identification of the SDGs relevant to the topics covered by the ERDF ROP and Interreg ADRION, relevant for the external context, through consultation with the stakeholders, identified and placed in order of relevance; identification of the SDGs target and actions that affect the selected targets, in compliance with the program result indicators; development of an accountability strategy that connects targets, actions and programs implementation methods; test of the reporting strategy and its connection with the specific development objectives of the Region (Pact for Employment and Climate); preparation of a report, declined through the SDGs, compared with the analyses carried out at a global, European and national level and disseminated with specific communication actions and further participation.

The research poses some limitations which are discussed below. The analysis was carried out on a very specific context and its applicability in other territorial contexts, at different scales, must be verified. The accountability and reporting elements for sustainability and public value are based on a predominantly corporate perspective that does not 
fully adapt to the operating methods and purposes of the cohesion policy that produce their development effects in the medium and long term.

In conclusion, in order to account for sustainable territorial development policies and strategies, the effects of which cannot be assessed immediately, it is necessary to develop paths and processes that also take into account the time lag between actions carried out and impacts and take into account the progressive approach, over time, to the set objectives. The development of this path deserves further investigation in the field, with a view to managing sustainability and the creation of public value which, starting from the results of our research, optimizes the operational methods of public interventions.

Author Contributions: All authors wrote the paper, and their primary individual contribution is as follows: Section 1 is to be ascribed to E.D.G., Sections 2 and 3 are to be ascribed to R.L.O., Section 4 and related sub-sections are to be ascribed to L.G. and A.M.L., and Section 5 is to be ascribed to E.D.G. All authors have read and agreed to the published version of the manuscript.

Funding: This research received no external funding.

Conflicts of Interest: The authors declare no conflict of interest.

\section{References}

1. European Union. Consolidated version of the Treaty on the Functioning of the European Union, Part three: Union policies and internal actions-Title XVIII: Economic, Social and Territorial cohesion, article 174 (ex-article 158 TEC). Off. J. 2008, $15,115$.

2. Samecki, P. Orientation Paper on Future Cohesion Policy; European Commissioner in Charge of Regional Policy: Brussels, Belgium, 2009.

3. Crescenzi, R.; Iammarino, S. Global investments and regional development trajectories: The missing links. Reg. Stud. 2017, 51, 97-115. [CrossRef]

4. Benneworth, P.; Dassen, A. A Strengthening Global_Local Connectivity in Regional Innovation Strategies: Implications for Regional Innovation Policy; OECD: Paris, France, 2011.

5. European Commission. Europe 2020. A Strategy for Smart, Sustainable and Inclusive Growth; Communication from the Commission COM; European Commission: Brussels, Belgium, 2010.

6. European Commission. An Introduction to EU Cohesion Policy 2014-2020. Available online: https://ec.europa.eu/regional_ policy/sources/docgener/informat/basic/basic_2014_en.pdf (accessed on 29 December 2020).

7. Crescenzi, R.; di Cataldo, M.; Giua, M. It's not about the money. EU funds, local opportunities, and Euroscepticism. Reg. Sci. Urban Econ. 2020, 84, 103556. [CrossRef] [PubMed]

8. di Cataldo, M. The impact of EU Objective 1 funds on regional development: Evidence from the U.K. and the prospect of Brexit. J. Reg. Sci. 2017, 57, 814-839. [CrossRef]

9. Broadbent, J.; Guthrie, J. Changes in the Public Sector: A Review of Recent "Alternative" Accounting Research. Account. Audit. Account. J. 1992, 5, 3-31. [CrossRef]

10. Broadbent, J.; Guthrie, J. Public sector to public services: 20 years of "contextual" accounting research. Account. Audit. Account. J. 2008, 21, 129-169. [CrossRef]

11. Lapsley, I. Research in Public Sector Accounting: An Appraisal. Account. Audit. Account. J. 1988, 1, 21-33. [CrossRef]

12. Steccolini, I. Accounting and the post-new public management: Reconsidering publicness in accounting research. Account. Audit. Account. J. 2019, 32, 255-279. [CrossRef]

13. Barberis, P. The New Public Management and A New Accountability. Public Adm. 1998, 76, 451-470. [CrossRef]

14. Mulgan, R. Comparing Accountability in the Public and Private Sectors. Aust. J. Public Adm. 2000, 59, 87-97. [CrossRef]

15. Sinclair, A. The chameleon of accountability: Forms and discourses. Account. Organ. Soc. 1995, 20, 219-237. [CrossRef]

16. Bryson, J.M.; Crosby, B.C.; Bloomberg, L. Public Value Governance: Moving Beyond Traditional Public Administration and the New Public Management. Public Adm. Rev. 2014, 74, 445-456. [CrossRef]

17. O'Flynn, J. From New Public Management to Public Value: Paradigmatic Change and Managerial Implications. Aust. J. Public Adm. 2007, 66, 353-366. [CrossRef]

18. Stoker, G. Public value management: A new narrative for networked governance? Am. Rev. Public Adm. 2006, 36, 41-57. [CrossRef]

19. Benington, J. Creating the Public in Order to Create Public Value? Int. J. Public Adm. 2009, 32, 232-249. [CrossRef]

20. Alford, J.R.; Yates, S. Mapping public value processes. Int. J. Public Sect. Manag. 2014, 27, 334-352. [CrossRef]

21. Hartley, J.; Alford, J.; Knies, E.; Douglas, S. Towards an empirical research agenda for public value theory. Public Manag. Rev. 2016, 19, 670-685. [CrossRef]

22. Moore, M. Creating Public Value: Strategic Management in Government, 5th ed.; Harvard University Press: Cambridge, MA, USA, 1995; pp. 27-75. 
23. Alford, J.; Hughes, O. Public Value Pragmatism as the Next Phase of Public Management. Am. Rev. Public Adm. 2008, 38, 130-148. [CrossRef]

24. Guthrie, J.; Marcon, G.; Russo, S.; Farneti, F. Public Value Management, Measurement and Reporting; Emerald: Bingley, UK, 2014; Volume 3.

25. Bebbington, J.; Unerman, J. Achieving the united nations sustainable development goals: An enabling role for accounting re-search. Account. Audit. Account. J. 2018, 31, 2-24. [CrossRef]

26. Kastberg, G.; Lagström, C. Processes of hybridization and de-hybridization: Organizing and the task at hand. Account. Audit. Account. J. 2019, 32, 710-726. [CrossRef]

27. Bebbington, J.; Larrinaga, C. Accounting and sustainable development: An exploration. Account. Organ. Soc. 2014, 39, 395-413. [CrossRef]

28. Guthrie, J.; Parker, L. Corporate social disclosure practice: A comparative international analysis. Adv. Public Interest Account. 1990, 3, 159-175.

29. de Villiers, C.; Sharma, U. A critical reflection on the future of financial, intellectual capital, sustainability and integrated re-porting. Crit. Perspect. Account. 2020, 70, 101999. [CrossRef]

30. International Integrated Reporting Council. Journey to Breakthrough; IIRC: London, UK, 2016.

31. Miller, P.; Rose, N.S. Governing the Present: Administering Economic, Social and Personal Life; Polity: London, UK, 2008.

32. Guthrie, J.; Martin-Sardesai, A. Contemporary challenges in public sector accounting. In New Trends in Public Sector Reporting: Integrated Reporting and Beyond; Manes-Rossi, F., Orelli, R.L., Eds.; Palgrave MacMillan: London, UK, 2020; pp. 1-14.

33. Kuroki, M.; Hirose, Y.; Motokawa, K. Accounting Research on Local Government Reporting: Literature Analysis Using Text Mining. SSRN Electron. J. 2018. [CrossRef]

34. Brown, R.; Ellwood, S.; Conrath-Hargreaves, A. The Conceptual Underpinnings of Recent Advances in International Public Sector Accounting Standards: Developing a Standard for Social Benefits. In Proceedings of the 22nd Annual Conference Financial Reporting and Business Communication, Bristol, UK, 5-7 July 2018.

35. Saliterer, I.; Sicilia, M.; Steccolini, I. Public Budgets and Budgeting in Europe: State of the Art and Future Challenges; Springer Science and Business Media LLC: Berlin/Heidelberg, Germany, 2017; pp. 141-163.

36. Arnaboldi, M.; Lapsley, I.; Steccolini, I. Performance Management in the Public Sector: The Ultimate Challenge. Financ. Account. Manag. 2015, 31, 1-22. [CrossRef]

37. Curristine, T. Performance Budgeting in OECD Countries. In Proceedings of the 6th Annual Meeting of Latin American Senior Budget Officials, Santiago, Chile, 28-31 January 2008.

38. Guthrie, J.; Manes-Rossi, F.; Orelli, R.L. Integrated reporting and integrated thinking in Italian public sector organizations. Med. Account. Res. 2017, 25, 553-557.

39. Martin-Sardesai, A.; Guthrie, J. Social report innovation: Evidence from a major Italian bank 2007-2012. Meditari Account. Res. 2019, 28, 72-88. [CrossRef]

40. Deidda Gagliardo, E. Il Valore Pubblico. La Nuova Frontiera Della Performance; Rirea: Roma, Italy, 2015.

41. Dumay, J.; Farneti, F.; Guthrie, J. GRI. Sustainability Reporting Guidelines for Public and Third Sector Organizations: A critical review. Public Manag. Rev. 2010, 12, 531-548.

42. Habek, P.; Wolniak, R. European Union Regulatory Requirements Relating to Sustainability Reporting. The Case of Sweden. Sci. J. 2013, 34, 40-47.

43. International Integrated Reporting Council. The International Integrated Reporting Framework; IIRC: London, UK, 2013.

44. Velte, P.; Stawinoga, M. Integrated reporting: The current state of empirical research, limitations and future research implications. J. Manag. Control. 2017, 28, 275-320. [CrossRef]

45. Stacchezzini, R.; Melloni, G.; Lai, A. Sustainability management and reporting: The role of integrated reporting for communicating corporate sustainability management. J. Clean. Prod. 2016, 136, 102-110. [CrossRef]

46. Stubbs, W.; Higgins, C. Integrated Reporting and internal mechanisms of change. Account. Audit. Account. J. 2014, 27, 1068-1089. [CrossRef]

47. Guthrie, J.; Adams, C.; Staib, R. Social and Environmental Reporting; Springer Science and Business Media LLC: Berlin/Heidelberg, Germany, 2005; pp. 159-165.

48. Smith, M.S.; Griggs, D.; Gaffney, O.; Ullah, F.; Reyers, B.; Kanie, N.; Stigson, B.; Shrivastava, P.; Leach, M.; O’Connell, D. Integration: The key to implementing the Sustainable Development Goals. Sustain. Sci. 2017, 12, 911-919. [CrossRef] [PubMed]

49. Deidda-Gagliardo, E. La Creazione del Valore Nell'ente Locale: Il Nuovo Modello di Governo Economico; Giuffrè: Milano, Italy, 2002.

50. Farneti, F.; Guthrie, J.; Canetto, M. Social Reports of an Italian Local Government: A Longitudinal Analysis. Meditari Account. Res. 2020, 27, 580-612. [CrossRef]

51. Farneti, F.; Guthrie, J. Sustainability reporting by Australian public sector organizations: Why they report. Account. Forum 2009, 33, 89-98. [CrossRef]

52. Guthrie, J.; Domingues, A.R.; Manes-Rossi, F.; Orelli, R.L. Integrated reporting and sustainable development goals in univer-sities. In Handbook of Integrated Reporting; de Villiers, C., Hsiao, P.K., Maroun, W., Eds.; Routledge: London, UK, 2020 ; pp. 419-439.

53. Adams, C.A. Debate: Integrated reporting and accounting for sustainable development across generations by universities. Public Money Manag. 2018, 38, 332-334. [CrossRef]

54. Adams, C.A. The International Integrated Reporting Council: A call to action. Crit. Perspect. Account. 2015, 27, 23-28. [CrossRef] 
55. Adams, C.A. Understanding Integrated Reporting: The Concise Guide to Integrated Thinking and the Future of Corporate Reporting; Greenleaf Publishing: London, UK, 2015.

56. Adams, C.A. The Sustainable Development Goals, Integrated Thinking and the Integrated Report; IIRC and ICAS: London, UK, 2017.

57. Adams, C.A. Conceptualizing the contemporary corporate value creation process. Account. Audit. Account. J. 2017, 30, 906-931. [CrossRef]

58. Flower, J. The International Integrated Reporting Council: A story of failure. Crit. Perspect. Account. 2015, 27, 1-17. [CrossRef]

59. KPMG. Integrated Reporting Issue 2: Performance Insight Through Better Business Reporting. Available online: https:// integratedreporting.org (accessed on 29 December 2020).

60. ACCA. Eurosif. What Do Investors Expect from Non-Financial Reporting? Available online: www.accaglobal.com (accessed on 29 December 2020).

61. United Nations. Resolution Adopted by the General Assembly on 25 September 2015. Transforming Our World: The 2030 Agenda for Sustainable Development. Available online: https: / / unric.org (accessed on 29 December 2020).

62. PwC. Implementing Integrated Reporting 2019. Available online: www.pwc.com (accessed on 29 December 2020).

63. Yin, R.K. Case Study Research: Design and Methods; Sage Publications: Newbury Park, CA, USA, 1989.

64. Eisenhardt, K.M. Building Theories from Case Study Research. Acad. Manag. Rev. 1989, 14, 532-550.

65. Bennett, A.; Elman, C. Qualitative Research: Recent Developments in Case Study Methods. Annu. Rev. Polit. Sci. 2006, 9, 455-476. [CrossRef]

66. Lincoln, Y.; Guba, E.G. Naturalistic Inquiry; Sage Publications: Newbury Park, CA, USA, 1985.

67. Guba, E.G.; Lincoln, Y.S. Paradigmatic Controversies, Contradictions, and Emerging Influences. In The Sage Handbook of Qualitative Research, 3rd ed.; Denzin, N.K., Lincoln, Y.S., Eds.; Sage Publications: Thousand Oaks, CA, USA, 2005; pp. 191-215.

68. van de Ven, A.H.; Poole, M.S. Explaining development and change in organizations. Acad. Manag. Rev. 1995, 29, 510-540. [CrossRef]

69. Brown, A.D.; Jones, M.R. Doomed to failure: Narratives of inevitability and conspiracy in a failed IS project. Organ. Stud. 1998, 19, 73-88. [CrossRef]

70. Eisenhardt, K.M.; Graebner, M.E. Theory Building from Cases: Opportunities and Challenges. Acad. Manag. J. 2007, 50, 25-32. [CrossRef]

71. Pettigrew, A.; Whipp, R. Managing Change for Competitive Success; Oxford: Blackwell, UK, 1991.

72. Hines, P.; Holweg, M.; Rich, N. Learning to evolve: A review of contemporary Lean Thinking. Int. J. Oper. Prod. Manag. 2004, 24, 994-1011. [CrossRef]

73. Pettigrew, A.; Ferlie, E.; McKee, L. Shaping strategic change-The case of the NHS in the 1980's. Public Money Manag. 1992, 12, 27-31. [CrossRef]

74. Iles, V.; Sutherland, K. Managing Change in the NHS: A Review for Health Care Managers, Professionals and Researchers; National Coordinating Centre for NHS; Service Delivery and Organisation R\&D: London, UK, 2001.

75. Stetler, C.; Ritchie, J.; Rycroft-Malone, J.; Schultz, A.; Charns, M. Improving quality of care through routine, successful implementation of evidence-based practice at the bedside: An organizational case study protocol using the Pettigrew and Whipp model of strategic change. Implement. Sci. 2007, 2, 1-13. [CrossRef]

76. Young, T.P.; McClean, S.I. A critical look at Lean Thinking in healthcare. Qual. Saf. Heal. Care 2008, 17, 382-386. [CrossRef]

77. Demeterova, B.; Fischer, T.; Schmude, J. The Right to Not Catch Up-Transitioning European Territorial Cohesion Towards Spatial Justice for Sustainability. Sustainability 2020, 12, 4797. [CrossRef]

78. Barca, F.; McCann, P.; Rodriguez-Pose, A. The case for regional development intervention: Place-based versus place-neutral approaches. J. Reg. Sci. 2012, 52, 134-152. [CrossRef]

79. Portaluri, P.P. La coesione politico-territoriale: Rapporti con l'Europa e coordinamento Stato autonomie. Federalismi 2016, $22,1-31$.

80. European Commission. Communication from the Commission: The European Green Deal, COM/2019/640 final; European Commission: Brussels, Belgium, 2019.

81. European Commission. Sustainable Europe Investment Plan. European Deal Investment Plan, COM/2020/21 final; European Commission: Brussels, Belgium, 2020.

82. European Commission. The Programming Period 2014-2020, Guidance Document on Monitoring and Evaluation. European Cohesion Fund and European Regional Development Fund. Concepts and Recommendations; European Commission: Brussels, Belgium, 2014.

83. Pîrvu, R.; Bădîrcea, R.M.; Manta, A.G.; Lupăncescu, M. The Effects of the Cohesion Policy on the Sustainable Development of the Development Regions in Romania. Sustainability 2018, 10, 2577. [CrossRef]

84. European Commission. What is the European Green Deal? Directorate—General for Communication; European Commission: Brussels, Belgium, 2019.

85. European Commission. A Strong Social Europe for Just Transition, COM/2020/14 Final; European Commission: Brussels, Belgium, 2020.

86. Emilia-Romagna Regionl Council. The Pact for Employment; Emilia-Romagna Region Council: Bologna, Italy, 2015.

87. Emilia-Romagna Region Council. The Pact for Employment and Climate; Emilia-Romagna Region Council: Bologna, Italy, 2020.

88. Katsikas, E.; Manes-Rossi, F.; Orelli, R. Towards Integrated Reporting-Accounting Change in the Public Sector; Springer: Cham, Switzerland, 2017. 
89. New Trends in Public Sector Reporting: Integrated Reporting and Beyond; Manes-Rossi, F.; Orelli, R.L. (Eds.) Palgrave MacMillan: London, UK, 2020.

90. Manes-Rossi, F.; Tiron-Tudor, A.; Nicolò, G.; Zanellato, G. Ensuring More Sustainable Reporting in Europe Using Non-Financial Disclosure-De Facto and De Jure Evidence. Sustainability 2018, 10, 1162. [CrossRef]

91. Emilia-Romagna Regionl Council. Programma di Mandato della Giunta Regionale. XI Legislatura; Emilia-Romagna Region Council: Bologna, Italy, 2020.

92. Emilia-Romagna Region Council. Documento di Economia e Finanza Regionale (DEFR); Emilia-Romagna Regionl Council: Bologna, Italy, 2020. 